\title{
Levels of $A B A$, its precursors and dehydrin-like proteins during mangrove leaf development and senescence
}

\author{
Flora AbdulRahman Ismail' ${ }^{1}$, Masoud, Muruke2 ${ }^{2}$ Jan W.M. Derksen ${ }^{3}$ and C. Mariani ${ }^{3}$ \\ ${ }^{\prime}$ Department of Botany University of Dar es Salam, P.O Box 35060 Dar es Salam, Tanzania; \\ ${ }^{2}$ Department of Molecular Biology and Biotechnology, University of Dar es Salaam, \\ P.O Box 35179, Dar es Salaam \\ ${ }^{3}$ Department of Plant Cell Biology, IWWR, RU Nijmegen, Toernooiveld 1, \\ 6525 ED Nijmegen, The Netherlands
}

Keywords: mangroves, Rhizophora mucronata, ABA, leaves, senescence, dehydrins.

\begin{abstract}
Abscisic acid (ABA) and dehydrin proteins are thought to confer tolerance to plant tissue under physiological stress and drought. Rhizophora mucronata, a true mangrove species, is subjected to physiological drought from fluctuating high saline conditions where leaf loss or senescence is considered a possible regulation mechanism to combat stress. Levels of ABA and proteins that cross reacted with an anti - dehydrin antibody were assessed through development with the aim of correlating these factors to physiological water stress or salinity stress in R. mucronata leaves. Younger leaves showed lower levels of ABA than mature and senescing leaves. In situ production and translocation from mature to younger leaves may contribute to these observations. The presence of ABA in senescing leaves is thought to be due to the presence of low levels of physiological activity. Proteins detected by anti-dehydrin antibody require cDNA confirmation, but the visibly increasing intensity of a band at $\sim 64 \mathrm{kDa}$ through development suggests potential correlation to drought or salinity stress which is expected to be maximal in maturing leaves. The absence of the dehydrin-like proteins in senescing leaves is postulated to be due to the lack of energy investment to synthesise these proteins in dying leaves.
\end{abstract}

\section{INTRODUCTION}

Leaf senescence is a form of terminal differentiation, a phenomenon essential for survival in plants. In promoting the death of their own cells, plants are able to survive harsh environmental conditions by reducing their water losses and energy requirement. Senescence in leaves is regulated by endogenous and environmental factors. Plant age, reproductive development, and levels of regulatory components such as hormones and reactive oxygen species represent known endogenous factors regulating senescence. Environmental cues affect leaf senescence in a ratio dependent manner, some increase whilst others decrease senescence. Factors increasing senescence include soil nutrient limitations, water deficiency, high salinity, and excessive heat, phyto-toxic compounds like ozone, high solar radiation and darkness. On the other hand, decapitation and the removal of flower and fruit, decrease senescence (Munné-Bosch and Alegre, 2002). 
Senescing leaves are readily identified by loss of chlorophyll manifested as a colour change from green to yellow or red. The colour change starts at the leaf margin gradually progressing towards the blade interior, a result of chlorophyll degradation following the disassembly of the chloroplasts and or anthocyanin accumulation. Simultaneous to the degradation of chlorophyll, a number of cellular proteins are degraded to their amino acid components and transported back to the plant via the vasculature. This is a form of nutrient recycling that allows the plant to retain valuable resources. Abscission, the final programme of leaf development is often associated with senescence. At this point, specific cells in the leaf petiole differentiate to form an abscission layer allowing the senescing leaf to separate from the plant (Taiz and Zeiger, 2002).

\section{$A B A$ and senescence}

The plant hormone Abscisic acid (ABA) is indirectly linked to senescence via its regulatory role in water deficiency stress. Endogenous levels of $\mathrm{ABA}$ are known to increase when plants are drought-stressed. In leaves the relation between ABA accumulation, stomatal resistance and water potential has been described for a number of species (Wang et al., 2001; Zhang and Outlaw, 2001). When leaf age is considered, stress-induced ABA accumulates to the greatest extent in young leaves of Xanthium strumarium despite the fact that mature leaves wilt earlier than younger ones (Cornish and Zeevaart, 1984). Based on these observations and other experiments, Cornish and Zeevart (1984) suggest higher ABA levels in young leaves to be a cumulative result of transport from older leaves and slow break down of ABA as opposed to in situ production only. The biosynthesis pathway of ABA has been shown to initiate from $\mathrm{C}_{40}$ carotenoids in plastids, which through a series of epoxidation reactions and cleavage form a $\mathrm{C}_{15}$ compound known as xanthoxin that is then transported to the cytosol and via subsequent reactions converted to $\mathrm{ABA}$.

\section{The mangrove leaf}

The mangrove environment is one of fluctuating salinity (35 ppt maximum) with an osmotic potential of $-2.5 \mathrm{MPa}$, the plants are thus subjected to physiological drought stress of variable extent. Additionally, the sediment is flooded periodically creating anaerobic conditions. A number of mechanisms have been developed in various tissue parts of mangroves to cope with stress. For example, to adapt to the redox state of the soil, some mangrove trees like Avicennia have developed specialised aerial roots known as pneumatophores that protrude out of the sediment enabling aeration. Other mangrove species possess stilt or aerial roots as seen in Rhizophora; these grow above the water into the sediment. The presence of lenticels is another adaptation seen in mangroves structural modifications on the shoots and roots (pneumatophores) that help exclude excessive salt uptake. Furthermore, the leaves of some mangroves like Avicennia show structural adaptations in the form of glandular structures on the epidermal surface that ensure excess salt uptake is accumulated and secreted.

In Rhizophora the leaves do not possess obvious structuralmodifications as anadaptation to the mangrove environment. Suggestions from early work on Rhizophora mangle are drawn from the observation of a thick leathery leaf and thick cuticle which may aid the plant to combat physiological drought stress (Feller, 1996 ). Generally, thick leathery, sclerophyllous leaves are characteristic of xeromorphic traits that prevail in dry environments where water is scarce. The rare occurrence of sclerophylly in wet environments where water is abundant is accounted for by physiological unavailability of water, i.e. water quality being not conducive for plant development (Read, 2003 \#192). Sclerophylly is thought to promote water retention and reduce loss by leaching from the plants. Studies that address the adaptive significance of this apparent xeromorphic trait in Rhizophora find little correlation with environmental stresses such as salinity 
(Camillier, 1983), and nutrient availability. This suggests that the sclerophyllous character of the leaves alone contributes little to protection of the plants in the mangrove environment (Feller, 1996). In the study by Feller (1996), sections of Rhizophora mangle leaf showed no sunken stomata, a feature characteristic to xerophytic species suggesting that Rhizophora is not a true xerophyte. These results suggest that there may be alternative mechanisms in Rhizophora leaves that combat the physiological drought stress, or that the plants may be evolving towards true xeromorphism.

In addition to structural mechanisms, some authors have suggested leaf abscission to be a mechanism by which mangroves can dispose of excess salt with the aim of protecting younger tissue (Munns, 1993; Hasegawa, et al., 2000). However, little is recorded in the literature on the relation between leaf development and water deficiency or salinity stress in mangroves. The only information available is of the influence of temperature, an indirect inducer of water stress, which plays a role in leaf abscission in mangroves. This information is extrapolated from leaf fall studies; leaves fall earlier in the hot and wet season and later in the cool relatively dry season (Tomlinson, 1996).

\section{Dehydrins}

Physiologically unavailable water and varying salinity extremes in the mangrove habitat present stressful conditions for survival. This form of stress is not unique to mangroves and is experienced by most plants due to their sessile nature not being able to avoid inevitable changes in the environment. A number of protective mechanisms to cope with stress exist at the cellular level. They include the expression (or production) of proteins that may protect the cell's metabolism (Ingram and Bartels, 1996). In particular, the expression/ production of a group of hydrophilic proteins known as dehydrins are a common response to water deficiency stress. Dehydrins are a class (D-II) of the Late Embryogenesis Abundant (LEA) family of proteins, which typically accumulate, in late embryogenesis in seed during desiccation, or in response to ABA. In vegetative tissues, factors that induce dehydrin expression include, low temperatures and other environmentally imposed stresses such as drought, and salinity (Close, 1996, 1997; Ingram and Bartels, 1996). A suggested function of dehydrins is that of cellular stabilisation via protein chaperoning and ion sequestration based on deductions from molecular structure and expression profiles under experimental conditions (Rorat, et al., 2004). In vegetative tissues of for example leaves, dehydrins are mainly expressed during dehydration and/or other environmental stresses.

In addressing $\mathrm{ABA}$ as a possible factor influencing senescence of mangrove leaves, a complementary study of dehydrin presence provides a wholesome scenario of potentially protective mechanisms involved in the development process.

Thus in this paper to discern the influence of ABA and dehydrins as a potential factors influencing senescence in mangrove leaves, we therefore ask the questions;

- Do the leaves of $R$. mucronata in vivo synthesise $\mathrm{ABA}$ in an age dependent manner possibly conferring a role in protection of younger leaves?

- Do the leaves of $R$. mucronata synthesise dehydrins and if so, does this occur in an age dependent manner and can this be correlated to salinity or physiological drought stress?

\section{MATERIALS AND METHODS}

\section{Leaf age and sampling}

Mangrove leaves were collected from $R$. mucronata stands in Mbweni fishing village $40 \mathrm{Km}$ from the city of Dar es Salaam in Tanzania. The Mbweni mangrove ecosystem is characterised by twice daily inundations with ocean water, which last for six hours and occasionally these are diluted with fresh water from a seasonal stream that flows through the area. 
Mangrove leaves grow to full size in a few weeks, meanwhile accumulating various ions in their vacuoles and then remain on the tree for months until senescence and abscission (Tomlinson, 1996). A new leaf pair is produced approximately every month, so the node number is approximately equal to the age of the leaf in months. Data are from leaves from four branches. Senescing leaves were identified as those that showed colour change from green to yellow.

Terminalbrancheswithattachedleaveswere placed in plastic bags and taken immediately to the laboratory where they were washed, categorized and subsequently lyophilised. The green leaves were subjectively grouped into five age classes based on nodal position and length (see Table 1); a sixth class was that of the yellowed, senescent leaves. Only leaves that fit the selected class criteria were used in the analyses to minimise differences that may result from overlapping samples. Likewise, differences in maximum surface area were eliminated as uniform weights from lyophilised tissue were used for the analyses.

\section{Extraction and Identification of carotenoids}

Slight modifications to a protocol from Parry et al. (1990) were employed. Briefly, $1 \mathrm{~g}$ of lyophilized tissue was ground in liquid nitrogen and suspended in $5 \mathrm{ml}$ cold ethanol with
Butylated-hydroxy-toluene (BHT 100mg/L, as an antioxidant) and $0.1 \% \mathrm{w} / \mathrm{v}$ Tri ethyl acetic acid (to maintain the alkaline $\mathrm{pH}$ ). The suspension was extracted for $12 \mathrm{hrs}$ on a shaker at $4^{\circ} \mathrm{C}$, and then centrifuged at $10,000 \mathrm{~g}$ and filtered through a Sep-Pak-C18 Waters column. Two back extractions for $6 \mathrm{hrs}$ were performed and extractions pooled and concentrated by evaporation under vacuum of $30^{\circ} \mathrm{C}$ till dry. The samples were then re-suspended in 1000 $\mu \mathrm{l}$ ethanol and $20 \mu \mathrm{l}$ aliquots were separated on an S5 ODS2-Spherisorb column with $4.6 \mathrm{~mm}$ i.d. The column was loaded on a $600 \mathrm{E}$ Waters reverse phase HPLC system controller. Elution was performed with a linear gradient of 10$50 \% \mathrm{Y}$ in $\mathrm{X}$ over $45 \mathrm{~min}$ at $1 \mathrm{ml} / \mathrm{min}$, where $\mathrm{X}$ is $85 \%$ methanol $(+0.1 \%$ Triethyl amine; $\mathrm{w} / \mathrm{v}$ ) and $\mathrm{Y}$ is $6: 4$ dichloromethane: methanol. The eluate was monitored at $440 \mathrm{~nm}$. Runs were done in duplicate. Internal standards for zeaxanthin and lutein (Fluka, Switzerland) and for neoxanthin and violaxanthin (Chromadex) were used to ascertain peak identity and calculate xanthophyll concentration.

\section{ABA sample purification for Enzyme Linked Immunosorbent Assay (ELISA)}

The samples in ethanol following the HPLC analysis $(\sim 960 \mu \mathrm{l})$ were further purified for Indirect ELISA according to a method from Davelaar (pers. comm.). Briefly, the samples

Table 1. Classes and characteristics for R. mucronata leaves sampled from Mbweni Fishing village. Nodal position indicates position from branch tip. Colour character considers all shades of green to be the same. Length and width of leaf blade only were measured; the petiole is not included in the analysis. Class sizes 4, 5 and 6 show no change in width

\begin{tabular}{cccc}
\hline Leaf class & Nodal position & Characteristics & Length / Width $(\mathrm{cm})$ \\
\hline L1 & 1 & Green & $10 / 4$ \\
L2 & 3 & Green & $14 / 6$ \\
L3 & 5 & Green & $16 / 8$ \\
L4 & 7 & Green & $18 / 10$ \\
L5 & 9 & Green & $20 / 10$ \\
6 L yellow & not considered & Yellow & $20 / 10$ \\
\hline
\end{tabular}


were evaporated to almost dryness. The resulting residue was taken up in $5 \mathrm{ml}$ phosphate buffer $\left(\mathrm{KH}_{2} \mathrm{PO}_{4} / \mathrm{Na}_{2} \mathrm{HPO}_{4}, 0.1 \mathrm{M}, \mathrm{pH}\right.$ 6.0) and then purified by passing through a column of polyvinylpolypyrrolidone (PVPP, 3X2 cm) in phosphate buffer $\mathrm{pH}$ 6.0. The resulting eluate at least $25 \mathrm{ml}$, was then acidified to $\mathrm{pH} 2.5\left(\mathrm{H}_{3} \mathrm{PO}_{4}\right)$ and partitioned three times against equal volumes of dichloromethane. The combined ABA containing dichloromethane layers were loaded on to a Sep-Pak silica Waters cartridge. ABA was eluted with $10 \mathrm{ml}$ methanol and evaporated until dry. The dried samples were stored at $-70^{\circ} \mathrm{C}$ until analysed. Prior to analysis the samples were taken up in $1000 \mu l$ of Tris buffered saline (TBS) of $\mathrm{pH} 7.8$.

\section{Indirect ELISA}

For the Indirect ELISA, the protocol for anti-ABA 15-I-C5 (Phytodek-ABA) was used. The anti-ABA 15-I-C5 (PhytodetekABA), obtained from Dr. E. Weiler, Bonn, Germany, is a mouse monoclonal antibody that is directed to ABA- $\mathrm{C}_{4}$ conjugates. This specificity is directed to bonding that alters the structure of ABA at the $4^{\text {th }}$ ring carbon in ABA-4'-p-aminobenzoyl hydrazone (ABA$\mathrm{ABH}$; synthesised according to Quarrie and Galfre, 1985). High maximum binding 96 well plates, were coated with rabbit anti-mouse immunoglobulin (RAMIG) at a concentration of $0.2-0.5 \mathrm{mg} / 20 \mathrm{ml}$ in carbonate buffer (pH 9.6) overnight at $4^{\circ} \mathrm{C}(200 \mu 1$ per well). The plates were then decanted by tapping out the RAMIG solution onto a clean dry cloth. Following this, the wells were incubated with $200 \mu \mathrm{l}$ of antibody solution $(0.05 \mathrm{mg}$ 15-I-C5/ $20 \mathrm{ml} \mathrm{NaHCO}_{3}$ or TBS, pH 7.8) overnight at $4{ }^{\circ} \mathrm{C}$. Following incubation, the plates were washed twice with sterile water and incubated with $100 \mu \mathrm{l}$ TBS and $50 \mu \mathrm{l}$ ABA standard or sample (diluted in TBS) for a minimum of $1 \mathrm{hr}$ at $4{ }^{\circ} \mathrm{C}$. The maximum binding (B max) wells were incubated with only $50 \mu \mathrm{l}$ TBS. For the competitive reaction step, $50 \mu \mathrm{l}$ of $\mathrm{ABA}-\mathrm{ABH}$-alkaline phosphatase conjugate (1: 1000 in TBS with
$0.1 \%$ gelatin (TBSG)) was added to each well and the plates were incubated at $4{ }^{\circ} \mathrm{C}$ for 3 hrs. The plates were then washed twice with water and incubated with $200 \mu \mathrm{l}$ per well of freshly prepared substrate solution for $1 \mathrm{hr}$ at $37^{\circ} \mathrm{C}$. The substrate solution consisted of 20 ml DEA-buffer (1M Diethanolamine, $0.5 \mathrm{mM}$ $\mathrm{MgCl} 2, \mathrm{pH} 9.8$ ) and $20 \mathrm{mg}$ para-Nitrophenyl phosphatase (pNPP). To stop the substrate reaction $50 \mu \mathrm{l}$ of $5 \mathrm{M} \mathrm{KOH}$ was added when the $\mathrm{B}$ max wells gave a reading of at least 1 on a Wallac Victor 21420 multilabel counter set at $405 \mathrm{~nm}$. An ABA standard series of (0.005/ 0.01/ 0.02/ 0.05/ 0.1/0.2/0.5/ 1/ 2/ $5)$ was used to determine ABA concentration of the respective samples.

\section{Protein isolation}

Lyophilised leaves were stored at $-70^{\circ} \mathrm{C}$ until extraction. A modified Hurkman and Tanaka (1986) protocol was employed for isolation of protein. $1 \mathrm{~g}$ of lyophilised sample was weighed and ground to a fine powder then suspended in extraction buffer (50mm Tris$\mathrm{HCl}, \mathrm{pH} 7.0 ; 0.7 \mathrm{M}$ sucrose; $50 \mathrm{mM}$ EDTA; $0.1 \mathrm{M} \mathrm{KCl} ; 2 \% \quad \beta$-mercaptoethanol; $2 \mathrm{mM}$ phenylmethylsulphonylfluoride (PMSF)) and an equal volume of Tris buffered $(\mathrm{pH} 8.8)$ phenol. Approximately, $1 \mathrm{ml}$ buffer to 10 $\mathrm{mg}$ tissue was used. The homogenates were incubated for at least $10 \mathrm{~min}$ on ice and then centrifuged at $16,000 \mathrm{~g}$ for $10 \mathrm{~min}$. The phenol phase with protein was then precipitated with 5 volumes of $0.1 \mathrm{M}$ ammonium acetate in $100 \%$ methanol overnight at $-20^{\circ} \mathrm{C}$. The precipitate was collected by centrifugation 20 min at $20,000 \mathrm{~g} / \mathrm{min}$ at $4^{\circ} \mathrm{C}$, and the resulting pellet washed twice with $0.1 \mathrm{M}$ ammonium acetate in methanol. Further purification was done by washing twice with $80 \%$ acetone and finally once with $70 \%$ ethanol. The final pellet was then placed in Sodium Dodecyl Sulphate (SDS) loading buffer (50mM Tris $\mathrm{HCl}, \mathrm{pH}$ $6.8 ; 20 \%$ glycerol; $10 \beta$-mercaptoethanol, $4 \%$ SDS). The total proteins were quantified using an amido black staining protocol adopted from (Dieckmann-Schuppert and Schnittler, 1997). 


\section{Western Blotting}

Approximately, $80 \mu \mathrm{g}$ of protein was loaded for sodium dodecyl sulfate polyacrylamide gel electrophoresis (SDS-PAGE). Polyacrylamide gels, $12.5 \%$, were run at $100 \mathrm{~V}$ for $2 \mathrm{hrs}$. One gel was then electro-blotted onto a $0.45-\mu \mathrm{m}$ pore-size nitro-cellulose membrane (Optitran BA-S 85, Schleicher and Schuell) for transfer of proteins. The nitrocellulose blotted with proteins was then dried between two Whatman filter papers at room temperature prior to Western Analysis. The second, counter gel was stained with Coomassie Blue for confirmation of protein loading. For Western Analysis, the nitrocellulose blot was washed twice with Tris Buffered Saline (pH 7.5) and non-specific binding was blocked with $10 \%$ skimmed milk powder in TBS overnight. The primary antibody against dehydrins (Close, et al., 1993) is directed to the K-segment consensus peptide which is characteristic of all dehydrins. Incubation of the blot with primary antibody diluted $1: 1,000$ in a $5 \%$ skimmed milk powder/ TBS buffer was carried out overnight at $4{ }^{\circ} \mathrm{C}$. Following primary antibody incubation the blots were then washed three times for $5 \mathrm{~min}$ in TBST (TBS with $0.1 \%$ Tween 20) and incubated in a secondary antibody, anti-rabbit immunoglobulin G-horse radish peroxidase (Sigma) diluted 1:20,000 in $5 \%$ milk/ TBS buffer for $60 \mathrm{~min}$. The blot was then washed thrice for $5 \mathrm{~min}$ with TBST. The proteins were detected using a West Pico Chemiluminescent (PIERCE) kit with premixed solutions in which the blot was rotated for 1 to $15 \mathrm{~min}$ before being exposed for 1 $15 \mathrm{~min}$ on film. The film was developed using a CEAPRO processor.

\section{Results and Discussion}

In this study an indirect approach was used, where endogenous ABA levels are considered to reflect the degree of stress and the function of a protective mechanism to determine the potential protection of young leaves from physiological drought and or excessive salt stress in $R$. mucronata.
The life span of Rhizophora mangle leaves averages 6-12 months with a maximum of 17 months growing one pair per month (Tomlinson, 1996). $R$. mangle is a close taxonomic relative of $R$. mucronata and as such is likely to exhibits similar growth and development patterns. Drawing on this postulated similarity, nodal leaf age was estimated at one month per leaf pair. The selected first five nodes for the green leaves imply that the age classes used ranged from $1-5$ or more months. The maximum leaf size was found at the fourth node indicating that this is representative of a mature leaf. Senescent leaves were selected based on the complete yellow coloration; they varied from the mature leaf only by nodal position as leaf size was similar. The various classes selected for analysis are thus considered representative samples for the variations observed through growth and development of $R$. mucronata leaves.

\section{ABA biosynthesis in $R$. mucronata leaves}

High standard deviations and inconsistent patterns of xanthophyll levels in $R$. mucronata leaves made it difficult to make reasonable interpretation from the HPLC analyses (see Fig. 1a and b). The anticipated decrease in xanthophylls as a result of $i n$ situ ABA synthesis with development was not obvious from the attained chromatograms. Additionally, the xanthophyll neoxanthin was not detected in any of the leaf samples. Neoxanthin in plants is found generally in lower concentrations than the other xanthophylls explaining the undetectable quantities (Bukhov, et al., (2001). This discrepancy can only be confirmed by further analysis.

The inclusion of lutein in the analyses as an internal control to eliminate peak misinterpretation also serves to confirm the normal development of $R$. mucronata leaves. Lutein is an $\beta$-derived xanthophyll and is found in generally higher concentrations than the B-derived xanthophylls (Bukhov et al., 2001) and is found in higher amounts in photosynthetically active leaves but is not part 

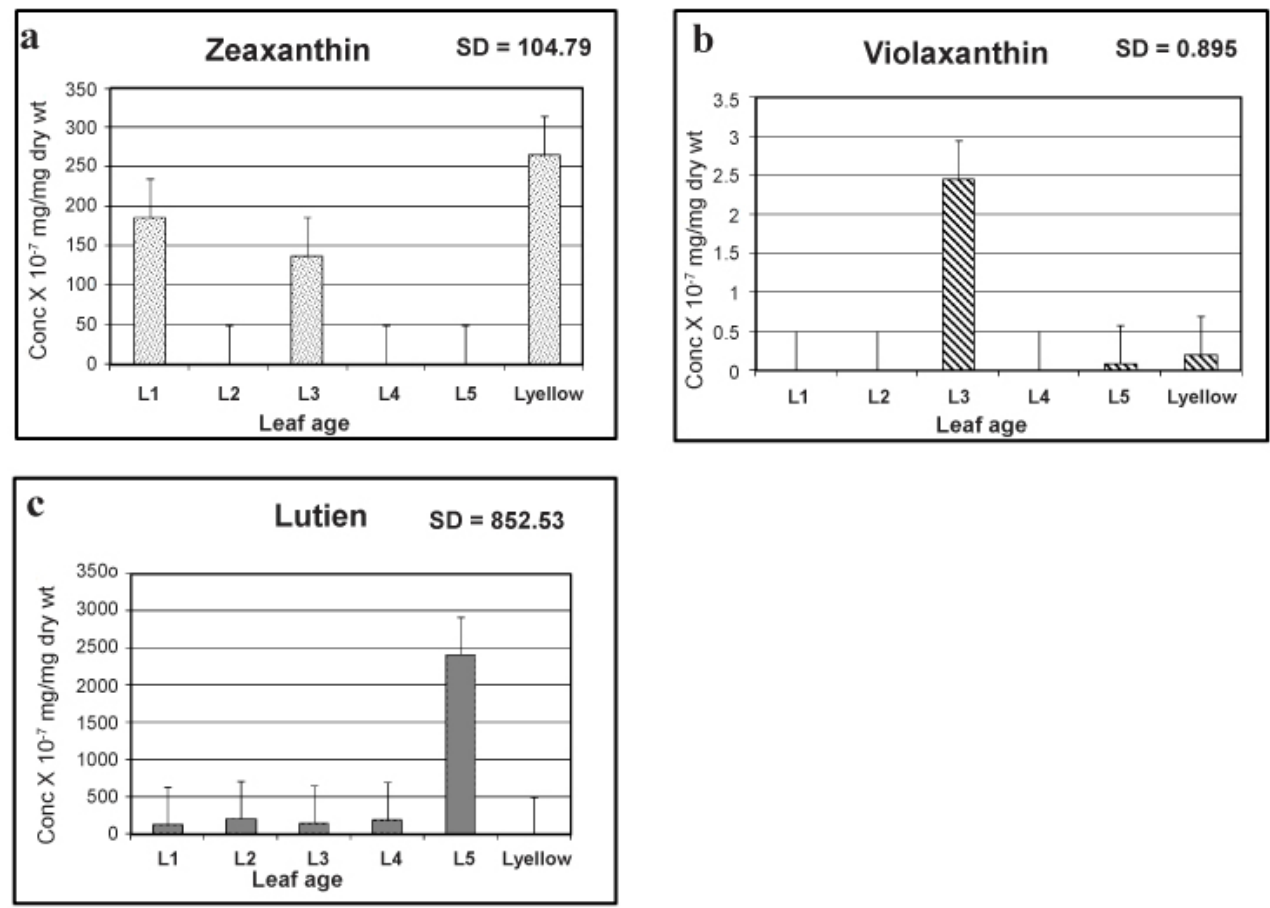

Fig. 1. (a) Zeaxanthin and (b) Violaxanthin levels for developing leaves of $R$. mucronata. (c) Lutein levels for developing leaves of $R$. mucronata

of the ABA biosynthetic pathway (See Fig. 1c). The absence of lutein in the senescent leaf conforms to the absence of a functional photosynthetic apparatus. Furthermore, prior to abscission metabolites from senescing leaves normally translocate to younger leaves where lutein recycling may be more efficient than that of zeaxanthin which was still detected in the senescing leaves. However, the continued presence of zeaxanthin in senescing leaves might be additionally attributed to its photo protective role via the xanthophyll cycle.

\section{Indirect ELISA}

The amount of ABA in $R$. mucronata was slightly higher in older leaves than in younger leaves. Leaves from L1 and L2 showed higher ABA than that of L3 and the L4 leaf showed the highest ABA levels. There was a lowering in ABA level in L5 (most mature leaf) whereas, the senescent leaf (L yellow) showed an increase in hormone levels (See
Fig. 2). A number of mechanisms may account for the observed profile. Though collected at a fixed time point, the different leaves are at different levels of physiological stress. The argument that mature leaves give up their ABA for younger leaves under stress conditions as posed by (Cornish and Zeevaart, 1984), may explain the profile observed in this study. The supposition that ABA is being recycled from senescing leaves would mean that the youngest leaves draw from the older leaves in a sequential manner i.e., from L5 to L4 and then to the younger leaves L3, L2 to L1. The presence of higher ABA levels in L4 as compared to L5 and L3 may be only transitory. In addition to translocation of $\mathrm{ABA}$, in situ synthesis in all leaf categories may account for some of the variation observed. The presence of high levels of ABA in the senescent leaves (L yellow) as compared to the younger leaves L1, L2 and L3 suggests that senescing leaves maintain some form of metabolic activity such that at the time of analysis ABA is detected as a 


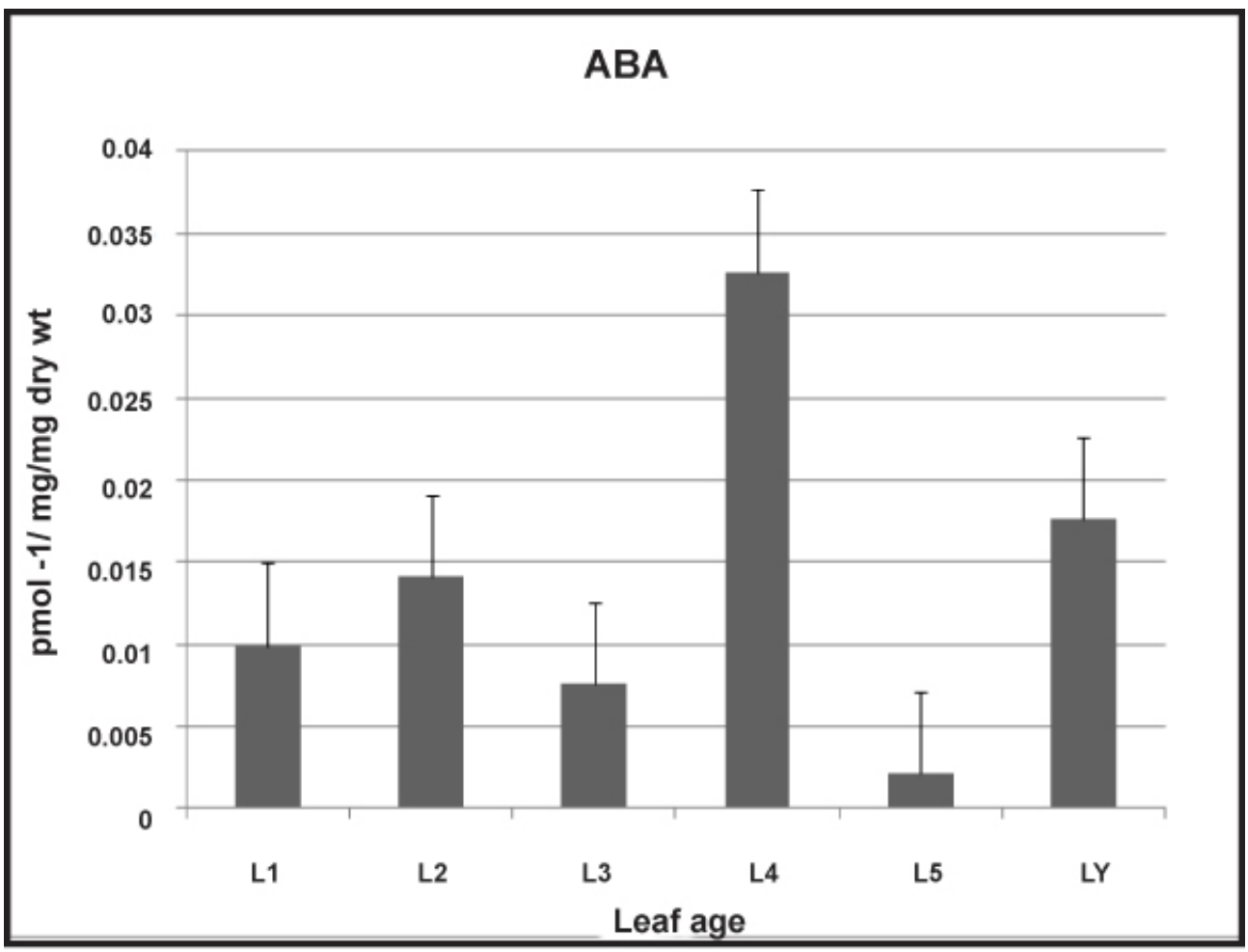

Fig. 2. ABA levels for developing leaves of $R$. mucronata

potential protective mechanism in the course of desiccation. For confirmation of this postulate an analysis including a range of yellowing to fully yellowed leaves should be examined to assess whether ABA levels are lowered in the most senescent (yellowed) leaves.

\section{Dehydrin expression}

Following the arguments of Cram, et al. (2002), the parent mangrove plant holds less salt when a leaf is abscised, but leaf loss does not separate salt from the plant as does the root where glands actively secrete salt. Unlike gland secretion of salt, leaf abscission removes salt and its associated biomass from the tree. Slim et al. (1996) found that, unlike other mangrove species, $R$. mucronata accumulates chloride ions with leaf age, and this increase is definitive during senescence suggesting that these leaves may be used as a sink for excess ions. Detection of dehydrin proteins during development of $R$. mucronata leaves would indicate that the plants possessed a functional mechanism for protection against potential drought and salinity stresses.

With the Western Analysis, a total of four different bands from the leaves of $R$. mucronata were detected by the anti-dehydrin antibody (See Fig. 3). The observed bands are regarded as dehydrin-like, due to lack of data from cDNA analyses to confirm the sequence and homology to known dehydrins. The detected bands ranged from approximately $68 \mathrm{kDa}$ to $34 \mathrm{kDa}$; known dehydrins range from as low as $9 \mathrm{kDa}$ to as large as $200 \mathrm{kDa}$ (Allugulova, et al., 2003). The $64 \mathrm{kDa}$ band was observed in all green leaves (L1 - L5), this band is suggested to be induced by the regular physiological fluctuations of salinity or drought stress that the entire plant experiences. The youngest leaf class (L1) showed the highest number of bands (4) with the largest at $\sim 66 \mathrm{kDa}$, followed by $64 \mathrm{kDa}$, and another at approximately 


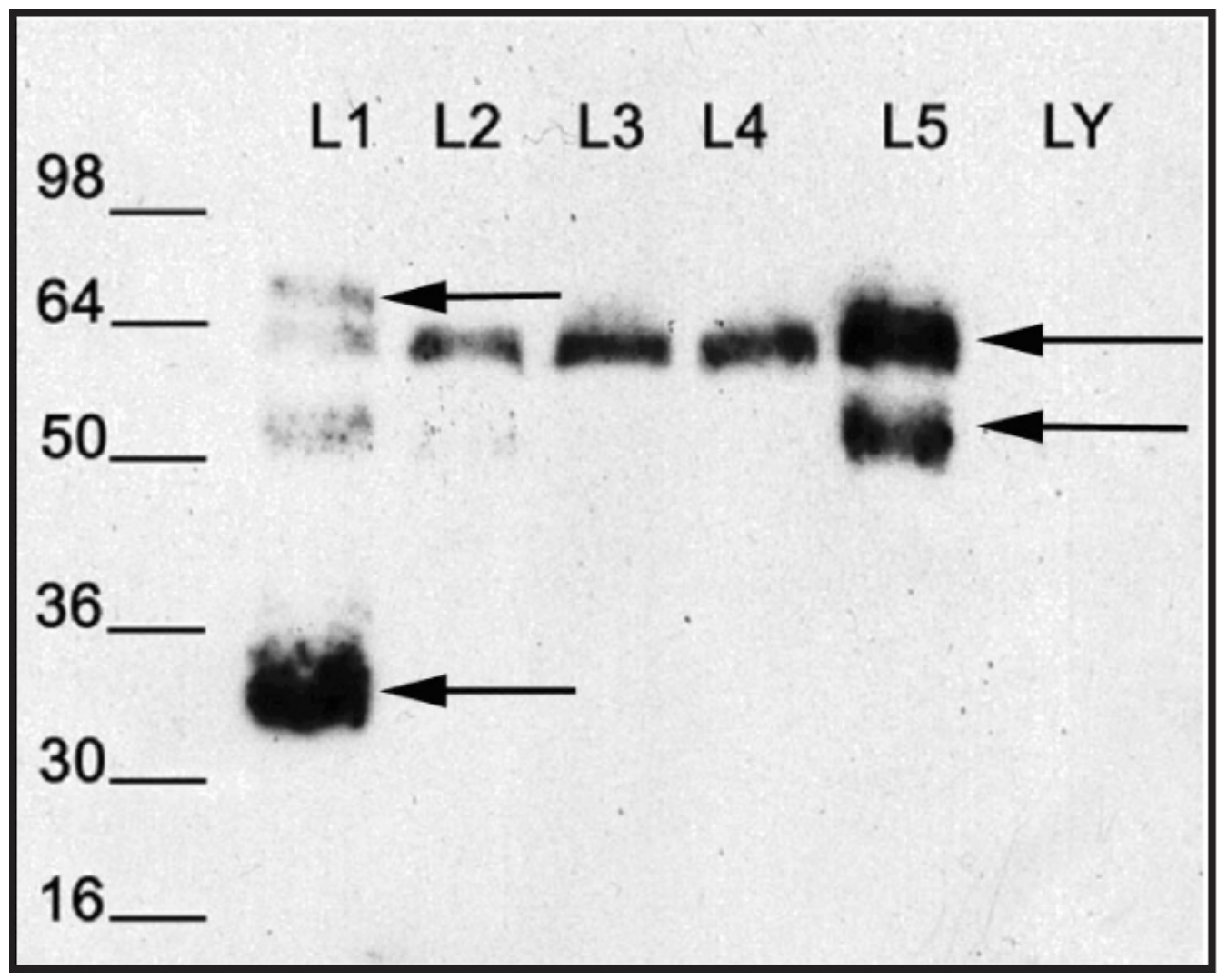

Fig. 3. Western Analysis of $R$. mucronata leaf development stages

$55 \mathrm{kDa}$ and finally the smallest one at $34 \mathrm{kDa}$. The second leaf class (L2) showed only slight detection for the $55 \mathrm{kDa}$ band suggesting low expression or overlap from L1, but a stronger detection for the $64 \mathrm{kDa}$ band. The third and fourth classes (L3 and L4) exhibited only a band at $64 \mathrm{kDa}$. The mature leaf (L5) had strong expression for both the $64 \mathrm{kDa}$ and $55 \mathrm{kDa}$ bands, no bands were detected in senescent leaves.

The $64 \mathrm{kDa}$ band observed in all the leaf classes with the exception of the senescing leaves increases with intensity suggesting a higher demand of the dehydrin - like protein through development. The results presented are from untreated material collected at consistent times from the field. Assuming that field conditions at any specific time are constant, the leaves would have been exposed to similar local and internal physio-chemical environmental conditions prior to collection. Thus the presence of stress associated proteins in the leaves of $R$. mucronata should reflect either a unique or common induction factor. The constitutive expression of the $64 \mathrm{Kda}$ dehydrin-like protein in leaves of $R$. mucronata is most likely a response to the constantly fluctuating salinity and redox levels of the mangrove environment. Another possibility for the constitutive expression of the $64 \mathrm{Kda}$ protein could be that it confers partial tolerance to desiccation. Most plants exhibit varying degrees of tolerance to desiccation and generally the combination of different stress inducing factors (e.g. drought, salinity) influences the mechanism or level of adaptation employed. For example, slow drying such as is expected in the mangrove environment when salinity levels rise with the incoming tide making the fresh water physiologically unavailable, 
on its own is generally detrimental to tissues that are not desiccation tolerant. But, slow desiccation and high relative humidity may confer some degree of tolerance, as the tissues may survive the water deficit by drawing on atmospheric water whilst developing the necessary mechanisms for protection against dehydration. Though water from the soil is physiologically unavailable in the mangrove environment at all times, relative air humidity is high. Thus, the constitutive expression of the 64 kda dehydrin-like protein in $R$. mucronata may serve as a buffer mechanism when the leaves switch from water loss by rising soil salinity to water uptake from the atmosphere when humidity levels are conducive. In the individual leaf classes the increased demand the $64 \mathrm{kDa}$ dehydrin-like protein expressed by intensity may account for the desiccation stress that each stage undergoes. Thus, L5 as the most mature leaf experiencing the highest degree of desiccation would naturally exhibit the highest intensity of $64 \mathrm{kDa}$ dehydrin-like protein.

$R$. mucronata leaves are not desiccation tolerant in that they do not fully recover when subjected to an extended period without water. Yet the presence of desiccation-associated proteins suggests that it possesses the necessary competence to cope with short term desiccation stress in leaves. Intriguingly, the $64 \mathrm{kDa}$ band is also expressed in reproductive tissue, i.e. the ovules, of $R$. mucronata (Ismail, et al., in press). However, the embryos are not desiccation tolerant. To explain this observation, two hypotheses can be drawn up, the first being that the same protein functions differently in different tissues of $R$. mucronata. The second hypothesis suggests that the presence of dehydrin-like proteins in $R$. mucronata does not confer extended desiccation tolerance as is required in seeds. This latter hypothesis is supported by some studies that describe dehydrins homologous to known sequences that are not involved in desiccation. Rorat et al. (2004) observed expression of such a dehydrin, DHN10 $(9.8 \mathrm{Kda})$ that was primarily regulated by organ type and for leaf development stage. These findings suggest that there may be alternative scenarios considering a wider occurrence and function of dehydrins in conditions not restricted to water and salinity stress as is generally thought.

The absence of dehydrin-like proteins in senescing leaves of Rhizophora adds information to the observations by Slim, et al. (1996) who suggested that excess salt would be deposited in the senescing leaves. Working on the presumption that the presence of dehydrins confers tolerance to salinity or drought stress, higher dehydrin expression indicates higher stress and absence of dehydrin implies lack of protection. Senescing leaves are at the terminal stage of existence on the parental plant and thus it is presumed that there should be little if any energy investment conferred to their continuance. Relegating their contribution to the survival of the plant to being a sink for unwanted toxic substances is confirmed by the absence of functional protective dehydrin proteins which would otherwise aid the leaves to combat the stress.

In mature leaves (L5) of $R$. mucronata, the additional band at $55 \mathrm{kDa}$ suggests that this protein may be specifically related to a different stress or the particular stage of development. A postulated function for this dehydrin-like protein is to provide additional protection to the mature leaf which acts as a channel to draw excess salt from the younger leaves $(\mathrm{L} 1-\mathrm{L} 4)$ and translocate it to senescing leaves as a means of removing excess salt from the plant. The presence of the $55 \mathrm{Kda}$ band in younger leaves ( $\mathrm{L} 1$ and L2) of $R$. mucronata further implies that this protein plays a complementary role to the $64 \mathrm{kDa}$ dehydrin-like protein in protecting the leaves against developmentally induced stresses that may arise as a result of function of the particular leaf stage. Younger leaves are vulnerable to physiological drought due to poorly developed sclerophyllous properties that would otherwise serve to prevent excessive water loss. The smallest band of dehydrin-like protein detected in L1 at 34Kda, is suggested to be either a breakdown product 
of the $68 \mathrm{Kda}$ protein or a dimer though no dimers have been recorded from any known dehydrin. No putative function is assigned to this protein or the $\sim 66 \mathrm{Kda}$ protein in $\mathrm{L} 1$, for this additional studies on this particular leaf class would need to be carried out.

The results on the precursor levels of ABA presented in this study are insufficient to establish grounds for correlation of recalcitrance with ABA biosynthesis and subsequent development. The differences in xanthophyll levels observed between developmental stages of the leaves can be either real, or they may be due to experimental errors as the sample sizes were relatively small. However, the results of this study do establish that $R$. mucronata leaves possess a functional mechanism for ABA synthesis as both precursor and product can be detected.

The dynamics of ABA in $R$. mucronata are not readily comparable to other species in that although there is the suggestion that there is translocation of the phyto-hormone from mature leaves to younger leaves older leaves maintain higher levels of ABA. This suggests that there is a higher in situ production of ABA in older and senescent leaves to allow protection of the desiccating leaves and supplying younger leaves with the hormone. The additional supply of ABA from older and senescing leaves in Rhizophora would provide ample protection to the younger leaves that do not possess a fully developed sclerophyllous leaf.

The absence of dehydrin-like proteins in senescing leaves contradicts the presence of ABA in these leaves as they are thought to be complementary mechanisms for protection during desiccation. The presented results suggest that though developmentally the senescing leaves invest no energy in the synthesis of desiccation proteins there remains some physiological protection offered in the form of ABA to the desiccating leaves.

Lastly, this study forwards the suggestion of complementary functions for two of the detected putative dehydrin-like proteins at $64 \mathrm{kDa}$ and $55 \mathrm{kDa}$ for some of the leaf classes. However, to determine the precise function of these proteins $R$. mucronata cDNA analysis, to assess the extent of homology to known sequences and protein expression under experimental dehydration conditions, will significantly contribute in discerning their developmental and physiological relationships.

Acknowledgements-We thank Professor E.J Weiler for generously providing the anti-ABA serum and protocol for the ELISA experiments and Professor Timothy J Close (University of California, Riverside) for his generous gift of dehydrin antibody.

\section{References}

Allugulova, C. R., Gimalov, F. R., Shakirova, F. M. and Vakhitov, V. A. (2003). The Plant Dehydrins: Structure and Putative Functions. Biochemistry (Moscow) 68: 945-951.

Bukhov, N. G., Kopecky, J., Pfündel, E. E., Klughammer, C. and Heber, U. (2001). A few molecules of zeaxanthin per reaction centre of photosystem II permit effective thermal dissapation of light energy in the photosystem II of a poikilohydric moss. Planta 212: 739-748.

Camillier, J. C. (1983). Leaf thickness of mangroves (Rhizophora mangle) growing in different salinities. Biotropica 15: 139-141.

Close, T. J. (1996). Dehydrins: emergence of a biochemical role of a family of plant dehydration proteins. Physiologia Plantarum 97: 795-803.

Close, T. J. (1997). Dehydrins: a commonality in the response of plants to dehydration and low temperature. Physiologia Plantarum 100: 291-296.

Close, T. J., Fenton, R. D. and Moonan, F. (1993). A view of plant dehydrins using antibodies specific to the carboxy terminal peptide. Plant Molecular Biology 23: 279-286.

Cornish, K. and Zeevaart, J.-A. D. (1984). Abscisic acid metabolism in Relation to water stress and leaf age in Xanthium strumarium. Plant Physiology 76: 1029-1035. 
Cram, J. W., Torr, P. G. and Derek, R. A. (2002). Salt allocation during leaf development and leaf fall in mangroves. Trees 16: 112-119.

Dieckmann-Schuppert, A., and Schinttler, H(1997). A simple assay for quantification of protein in tissue sections, cell cultures, and cell homogenates, and of protein immobilized on solid surfaces. Cell Tissue Res. 288: 119126.

Feller, I. C. (1996). Effects of nutrient enrichment on leaf anatomy of dwarf Rhizophora mangle L., (Red mangrove). Biotropica 28: 13-22.

Hasegawa, P. M., Bressan, R. A., Zhu, J. K. and Bonhert, H. J. (2000). Plant cellular and molecular responses to salinity. Ann. Rev. Plant Physiol. Plant Mol. Biol 51: 463-499.

Hurkman, M. A. and Tanaka, C. K. (1986). Solubilization of plant membrane proteins for analysis by two-dimensional gel electrophoresis. Plant Physiol. 81: 802-806.

Ingram, J. and Bartels, D. (1996). The molecular basis of dehydration tolerance in plants. Annual Review Of Plant Physiology And Plant Molecular Biology 47: 377-403.

Ismail, F; Wolters-Arts,M. C; Nitsch, L, Derksen, $\mathrm{J}$ and Mariani, C (accepted 8th December 2009). Embryo development and dehydrin expression in the mangrove Rhizophora mucronata Lam. Sexual Plant Reproduction

Munné-Bosch, S. and Alegre, L. (2002). Die and let live: Leaf senescence contributes to plant survival under drought stress. Functional Plant Biology 31: 203-216.

Munns, R. (1993): Physiological processes limiting plant-growth in saline soils - some dogmas and hypotheses. Plant Cell Environment 16: 15-24.
Parry, A. D., Babiano, M. J. and Horgan, R. (1990): The role of cis-carotenoids in abscisic acid biosynthesis. Planta 182: 118-128.

Quarrie, S. A. and Galfre, G. (1985). Use of different Hapten-Protein Conjugates Immobilized on Nitrocellulose to Screen Monoclonal Antibodies to Abscisic acid. Analytical Biochemistry 151: 389-399.

Read, J. and Sanson, G. D. (2003). Characterizing sclerophylly: the mechanical properties of a diverse range of leaf types. New Phytologist 160: 81 .

Rorat, T., Grygorowicz, W., Irzykowski, P. and Rey, P. (2004). Expression of KS-type dehydrins is primarily regulated by factors related to organ type and leaf developmental stage during vegetative growth. Planta 218: 878-885.

Slim, F. J., Gwada, P. M., Kodjo, M. and Hemminga, M. A. (1996). Biomass and litterfall of Ceriops tagal and Rhizophora mucronata in the mangrove forest of Gazi bay, Kenya. Mar. Freshw. Res. 47: 999-1007.

Taiz, L. and Zeiger, E. (2002). Plant Physiology (Sinauer Associates, Inc., Massachusetts).

Tomlinson, P. B. (1996). The Botany of Mangroves (Press syndicate of the University of Cambridge, Melbourne).

Wang, X.-Q., Ullah, H., Jones, A. M. and Assmann, S. M. (2001). G-Protein regulation of ion channels and Absicisc acid signaling in Arabidopsis Guard cells. Science 292: 20702072.

Zhang, S. Q. and Outlaw, W. H. J. (2001). The guard-cell apoplast as a site of abscisic acid accumulation in Vicia faba L. Plant, Cell and Environment 24: 347-355. 